\title{
Short-term vagus nerve stimulation reduces myocardial apoptosis by downregulating microRNA-205 in rats with chronic heart failure
}

\author{
YANHUA XUAN $^{1,2}$, SHUANGSHUANG LIU $^{1}$, YAN LI $^{3}$, JING DONG $^{1}$, \\ JIAYING LUO ${ }^{1}$, TAO LIU ${ }^{4}$, YUANZHE JIN $^{2}$ and ZHIJUN SUN ${ }^{1}$ \\ ${ }^{1}$ Department of Cardiology Medicine, Shengjing Hospital of China Medical University, Shenyang, \\ Liaoning 110022; ${ }^{2}$ Department of Cardiology Medicine, Fourth Affiliated Hospital of China Medical University, \\ Shenyang, Liaoning 110032; ${ }^{3}$ Department of Geriatrics, Shengjing Hospital of China Medical University, Shenyang, \\ Liaoning 110022; ${ }^{4}$ Department of Geriatrics, Peoples' Hospital of Jilin City, Jilin 132000, P.R. China
}

Received July 11, 2016; Accepted July 11, 2017

DOI: $10.3892 / \mathrm{mmr} .2017 .7344$

\begin{abstract}
Previous studies have reported that short-term vagus nerve stimulation (VNS) improves cardiac function in rats with chronic heart failure (CHF). The molecular mechanisms are unclear. The potential effect of microRNA (miR)-205 in apoptosis of short-term VNS was examined. A total of 3 weeks after inducing CHF, the rats were divided into three groups: Sham stimulation in sham operated rats, sham stimulation in CHF rats (CHF-SS), and treated with VNS in CHF rats (CHF-VNS). The right vagus nerve of the neck was stimulated for $72 \mathrm{~h}$ in CHF rats with rectangular pulses of $40 \mathrm{msec}$ duration at $1 \mathrm{~Hz}$ and $5 \mathrm{~V}$. miR-205 was focused on, which exhibited differential expression in the miRNA microarray analysis of CHF rats, and the effects of VNS on apoptosis were examined. It was verified that the expression level of miR-205 in the CHF-SS group was increased, and the expression was reduced in the CHF-VNS group. Furthermore, mimics or inhibitor of miR-205 was transfected into H9c2 to investigate its function on apoptosis. Baculoviral IAP repeat-containing protein 2 (Birc2) was confirmed a target of miR-205 through a dual luciferase reporter assay and western blotting. It was demonstrated that downregulated miR-205 decreased apoptosis in $\mathrm{H} 9 \mathrm{c} 2$ cells. The apoptosis-associated proteins were further detected in $\mathrm{H} 9 \mathrm{c} 2$ cells and rat tissue. The mRNA and protein expression levels of caspase-3 and Bcl-2-associated X protein were decreased in the CHF-VNS group, the expression of Birc2 and B-cell lymphoma 2 were increased. The results
\end{abstract}

Correspondence to: Professor Zhijun Sun, Department of Cardiology Medicine, Shengjing Hospital of China Medical University, 39 Huaxiang Road, Shenyang, Liaoning 110022, P.R. China

E-mail: sunzj_sjcmu@163.com

Key words: vagus nerve, electric stimulation, heart failure, microRNA-205, baculoviral IAP repeat-containing protein 2, apoptosis were consistent with the in vitro study in the miR-205 inhibitor group. The present study demonstrated that short-term VNS decreased apoptosis by downregulating miR-205 in rats with CHF. Therefore, the results of the present study provide basic evidence for short-term VNS in the clinical treatment of CHF.

\section{Introduction}

Chronic heart failure (CHF) is the end stage of various cardiovascular diseases and poses a serious threat to human health, as it responds poorly to treatment (1). Previous clinical investigations demonstrated that long-term vagus nerve stimulation (VNS) therapy reduces ventricular remodeling and improves cardiac function, and increases exercise tolerance and the quality of life following CHF (2-4). Our previous study has demonstrated that short-term VNS also improves left ventricular function in rats with CHF (5). However, the molecular mechanisms of short-term VNS treatment remain unclear.

MicroRNAs (miRNAs/miRs) are highly conserved, endogenous, single-stranded non-coding small RNA molecules. miRNAs regulate gene expression by promoting degradation of target mRNA and (or) inhibiting translation. miRNAs involve cellular differentiation, proliferation, apoptosis and development processes of a variety of biological tissues (6). Previous studies have identified that specific miRNAs participate in the pathology of heart disease development, particularly in the progression of heart failure (HF) (7-10). Myocardial apoptosis is also involved in the development of HF $(11,12)$. Reducing cardiac damage is a potential therapeutic target for HF (13). miRNAs are also essential for regulation of cardiomyocyte apoptosis $(14,15)$.

Our earlier study hypothesized that miRNAs may be cardioprotective of short-term VNS in rats with CHF. Therefore, the differential expression of miRNAs was assessed using microarray analysis (16). The present study focused on miR-205, which was upregulated after the treatment with sham stimulation (SS) and downregulated after the treatment with short-term VNS following CHF in rats. In addition, the present study selected baculoviral IAP repeat-containing protein 
2 (Birc2), an inhibitor of apoptosis protein, as a predicted target gene of miR-205 through bioinformatics analysis. It was demonstrated that downregulated miR-205 increased Birc2 expression and reduced cardiac apoptosis in CHF rats.

\section{Materials and methods}

Rat model of CHF and VNS. The Animal Center of the Chinese Academy of Medical Sciences (Beijing, China) provided 58 male Wistar rats (7-8 weeks of age; weighing 250-300 g) to prepare the CHF model in the present study. The use of all rats was in strict compliance with the provisions of Animal Research Ethics Committee of Shengjing Hospital of China Medical University (Shenyang, Liaoning, China). The rats were kept in a stainless-steel net cage under standard laboratory conditions $\left(25^{\circ} \mathrm{C}\right.$; relative humidity $60 \%$; 12-h light/dark cycle) with free access to food and water. All animals were randomly divided into three groups: i) treated with SS in sham operated rats (SO-SS group, $\mathrm{n}=8$ ), ii) treated with SS in CHF rats (CHF-SS group, $n=8$ ), and iii) treated with VNS in CHF rats $(\mathrm{CHF}-\mathrm{VNS}$ group, $\mathrm{n}=8$ ). As described previously, a thoracotomy was performed under $1 \%$ pelltobarbitalum natricum $(40 \mathrm{mg} / \mathrm{kg}$ ) anesthesia administered via an intraperitoneal injection. The left anterior descending coronary artery was ligated firmly with prolene suture (Ethicon, Inc., Cincinnati, $\mathrm{OH}, \mathrm{USA})$ to produce myocardial infarction $(17,18)$. The left anterior descending coronary artery was tied loosely in the SO-SS group. At 3 weeks after the myocardial infarction operation, echocardiography was performed on the surviving rats. The rats with an infarction area $>40 \%$ of the left ventricular wall area were enrolled for research (5). This method of research was approved by the ethics committee of Shengjing Hospital of China Medical University (Shenyang, Liaoning, China).

As described in our previous study (5), a pair of Teflon-coated stainless steel wires (UL1330; Triumph Cable Co., Ltd., Dongguan, Guangdong, China) was looped around the right vagus nerve in the neck for electrical stimulation. The wires were connected to the output terminals of the stimulator (BL-420S Data Acquisition \& Analysis System; Chengdu Tme Technology Co, Ltd., Chengdu, Sichuan, China). Rectangular pulses were used at $1 \mathrm{~Hz}, 5 \mathrm{~V}$ and $40 \mathrm{msec}$ duration for $72 \mathrm{~h}$ to stimulate the vagus nerve.

Cardiac tissue preparation. The rats were sacrificed following $72 \mathrm{~h}$ of treatment. For each rat, the whole heart tissue was rapidly excised and washed with cold phosphate buffer. Heart tissues were frozen at $-80^{\circ} \mathrm{C}$ for reverse transcription-quantitative polymerase chain reaction (RT-qPCR) and western blot analysis.

Cell culture. The H9c2 rat myoblasts and 293T human renal epithelial cells (Cell Bank of the Chinese Academy of Sciences, Shanghai, China) were cultured in Dulbecco's modified Eagle's medium (Gibco; Thermo Fisher Scientific, Inc., Waltham, MA, USA) containing 10\% (v/v) FBS (Hyclone; GE Healthcare Life Sciences, Logan, UT, USA) at $37^{\circ} \mathrm{C}$ in a mixed atmosphere of $5 \% \mathrm{CO}_{2}$ and $95 \%$ air.

Cell transfection. Cell transfection was carried out using Attractene Transfection reagent (Qiagen GmbH, Hilden,
Germany) following the manufacturer's protocol. miR-205 mimics $\left(m i R-205_{m}\right)$, miR-205 inhibitor $\left(m i R-205_{i}\right)$ and matched negative controls $\left(\mathrm{NC}_{\mathrm{m}}\right.$, negative control mimics; $\mathrm{NC}_{\mathrm{i}}$, negative control inhibitor) were synthesized by GE Healthcare Dharmacon, Inc. (Lafayette, CO, USA). The level of miRNA expression in the cells was assayed by RT-qPCR.

miRNA microarray analysis. The miRNA microarray analysis was performed by Kangchen Biotech Co., Ltd. (Shanghai, China). Total RNA was extracted using TRIzol reagent (Invitrogen; Thermo Fisher Scientific, Inc.) and an miRNeasy mini kit (Qiagen $\mathrm{GmbH}$ ) according to manufacturer's protocol. The RNA quantity was measured using the NanoDrop 1000. The samples were labeled using the miRCURY ${ }^{\mathrm{TM}} \mathrm{Hy} 3^{\mathrm{TM}} / \mathrm{Hy} 5^{\mathrm{TM}}$ Power labeling kit and hybridized on the miRCURY ${ }^{\mathrm{TM}}$ LNA Array (v.18.0). Following the washing steps, the slides were scanned using the Agilent Scanner G2505C. Scanned images were imported into GenePix Pro 6.0 software (Molecular Devices, LLC, Sunnyvale, CA, USA) for grid alignment and data extraction. In screening for differentially expressed miRNAs, the threshold was set at fold difference $\geq 1.5$ or $\leq 0.67$, and $\mathrm{P}<0.05$. Hierarchical clustering was performed to demonstrate distinguishable miRNA expression profiling among samples.

$R T-q P C R$. All assays strictly followed the manufacturer's protocol.TotalRNA isolation was achieved using TRIzolreagent (Invitrogen; Thermo Fisher Scientific, Inc.). A PrimeScript RT kit (Takara Biotechnology Co., Ltd., Dalian, Liaoning, China) was used to create the cDNA library. RT-qPCR was performed using SYBR Premix Ex Taq II (Takara Biotechnology, Co., Ltd.) on a LightCycler 480 Real-Time PCR system (Roche Diagnostics, Basel, Switzerland). For qPCR, $1 \mu \mathrm{g}$ total RNA from each sample was resuspended in $20 \mu 1$ final volume of reaction buffer. Relative quantification was based on U6 and $\beta$-actin controls. All reactions were performed in triplicate and three dishes were prepared in each group in $\mathrm{H} 9 \mathrm{c} 2$ cells. The sequences of the primer pairs used were as follows: miR-205 forward, 5'-GCGTCCTTCATTCCACCG-3' and reverse, 5'-GTCGTATCCAGTGCAGGGTCCGAGGTATTCGCA CTGGATACGACACAGACTC-3'; U6 forward, 5'-CTCGCT TCGGCAGCACATATACT-3' and reverse, 5'-AAAATATGG AAGGCTTCACAGATTTG-3'; Birc2 forward, 5'-CAGCTT TGTGCAGACTTTGCTTTC-3' and reverse, 5'-CCTTGT TCCAGAGGTAGCGAGTG-3'; caspase-3 forward, 5'-AGA TACCAGTGGAGGCCGAC-3' and reverse, 5'-CACGAG TGAGGATGTGCATGA-3'; Bcl-2-associated X protein (Bax) forward, 5'-CTGACATGTTTGCAGACGGC-3' and reverse, 5'-AAGTCCAGTGTCCAGCCCAT-3'; B-cell lymphoma 2 (Bcl-2) forward, 5'-TGGTGGACAACATCGCTCTG-3' and reverse, 5'-GAGAAATCAAACAGAGGTCGCA-3'; $\beta$-actin forward, 5'-ATAGCACAGCCTGGATAGCAACGTAC-3' and reverse, 5'-CACCTTCTACAATGAGCTGCGTGTG-3'. The PCR was performed as follows: $95^{\circ} \mathrm{C}$ for $30 \mathrm{sec} ; 40$ cycles of $95^{\circ} \mathrm{C}$ for $5 \mathrm{sec}$ and $60^{\circ} \mathrm{C}$ for $30 \mathrm{sec} ; 95^{\circ} \mathrm{C}$ for $5 \mathrm{sec}, 60^{\circ} \mathrm{C}$ for $60 \mathrm{sec} ; 50^{\circ} \mathrm{C}$ for $30 \mathrm{sec}$. Fold changes relative to control samples were calculated using the $2^{-\Delta \Delta C q}$ method (19).

miR-205 target prediction. For predicting the potential target gene of miR-205, a bioinformatics approach was implemented, 

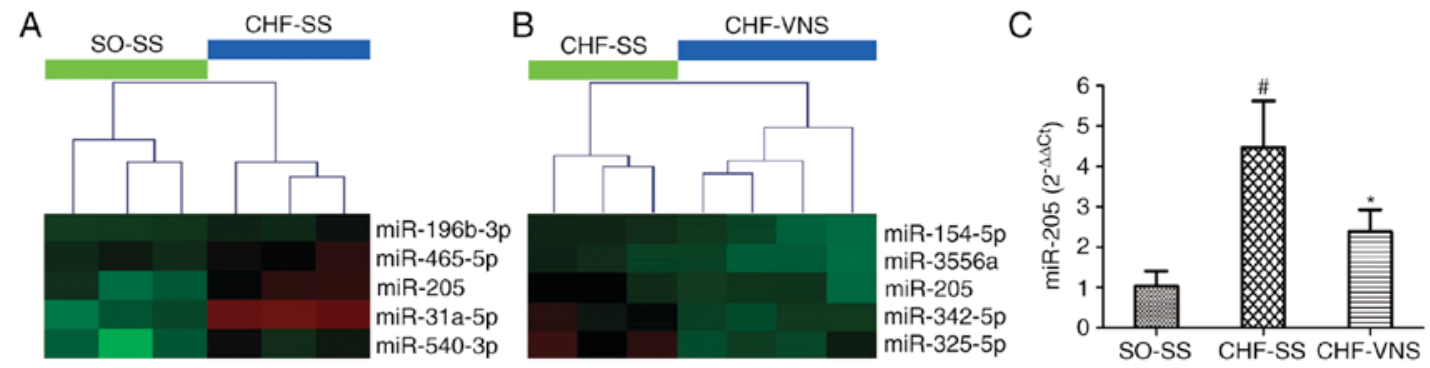

Figure 1. Fragment of miR-205 in the miR expression profile of the cluster diagram and the verification in myocardial tissue. (A) The CHF-SS vs. SO-SS group, and (B) the CHF-VNS vs. CHF-SS group. Green represents downregulation and red represents upregulation. (C) The expression level of miR-205 in myocardial tissue. Data are expressed as the mean \pm standard deviation. ${ }^{~} \mathrm{P}<0.05$ vs. SO-SS; ${ }^{*} \mathrm{P}<0.05$ vs. CHF-SS. miR, microRNA; SO, sham-operated; CHF, chronic heart failure; SS, sham stimulation; VNS, vagus nerve stimulation.

using miRanda (www.microrna.org/microrna/getDownloads. do), TargetScan (version 6.2; www.targetscan.org/) and miRWalk algorithm (version 2.0; zmf.umm.uni-heidelberg. de/apps/zmf/mirwalk2/genepub.html). The common prediction results of three databases were used as candidate genes. Birc2, an inhibitor of apoptosis protein, was selected as a predicted target gene of miR-205.

Dual luciferase reporter gene assay. The mutant 3'UTR and wild-type 3'UTR of Birc2 were inserted downstream of firefly luciferase in pmiR-Glo to form a luciferase reporter construct. 293T human renal epithelial cells were co-transfected with miR-205 and mutant pmiR-Glo-Birc2-3'UTR or wild-type pmiR-Glo-Birc2-3'UTR (Shanghai GenePharma Co., Ltd., Shanghai, China). Using Lipofectamine 2000, plasmid DNA and miR-205 $/ \mathrm{NC}_{\mathrm{m}}$ were co-transfected into $293 \mathrm{~T}$ cells. After $24 \mathrm{~h}$, luciferase activity was measured using the Dual-Luciferase Assay system (E1960, Promega Corporation, Madison, WI, USA) and a Multilabel Plate Reader (PerkinElmer, Inc., Waltham, MA, USA). Normalized luciferase activity was calculated as the ratio of Renilla and firefly luciferase activities.

Western blotting. SDS lysis buffer was used to extract total protein of rat tissues, and radioimmunoprecipitation assay lysis buffer was used for lysis of H9c2 cells (Beyotime Institute of Biotechnology, Shanghai, China). Proteins (40 $\mu \mathrm{g})$ were separated by $12 \%$ SDS-PAGE and transferred to polyvinylidene fluoride membranes (Roche Diagnostics), blocked using $15 \%$ skimmed milk (Yili Group, Inner Mongolia, China). Membranes were incubated overnight at $4^{\circ} \mathrm{C}$ with primary antibodies against Bcl-2 (mouse monoclonal; 1:2,000 dilution; cat. no. sc-7382; Santa Cruz Biotechnology, Inc., Santa Cruz, CA, USA), caspase-3 (rabbit polyclonal; 1:500 dilution; cat. no. sc-7145; Santa Cruz Biotechnology, Inc.), Bax (mouse monoclonal; 1:500 dilution; cat. no. sc-7480; Santa Cruz Biotechnology, Inc.), Birc2 (rabbit polyclonal; 1:500 dilution; cat. no. bs-4262R; BIOSS, Beijing, China) and $\beta$-actin (mouse monoclonal; 1:1,000 dilution; cat. no. bsm-33036m; BIOSS). The blots were then incubated at $37^{\circ} \mathrm{C}$ for $45 \mathrm{~min}$ with a horseradish peroxidase-conjugated goat anti rabbit immunoglobulin G secondary antibody (1:5,000; cat. no. A0208; Beyotime Institute of Biotechnology). A UVP Bioimaging system (BioSpectrum 410; UVP Inc., Upland, CA, USA) and Gel-Pro-Analyzer software version 5.0 (Media Cybernetics,
Inc., Bethesda, MD, USA) were used for detection and analysis. For H9c2 cells, three dishes were prepared in each group, and experiments were repeated three times.

TdT-mediated dUTP nick end labeling (TUNEL) assay. According to manufacturer's protocol, a TUNEL kit was used to detect cell apoptosis (cat. no. 11684817910; Roche Diagnostics). H9c2 cells were seeded into 12-well plates; $1 \mathrm{ml}$ of cell suspension was inoculated with $2 \times 10^{5}$ cells/well. Cells were fixed with $4 \%$ paraformaldehyde at room temperature for $30-60 \mathrm{~min}$, and then permeabilized with a $0.1 \%$ Triton X-100 solution (50 $\mu \mathrm{l}$; cat. no. ST795; Beyotime Institute of Biotechnology) in an ice bath for 2-5 min. Cells were then quenched of endogenous peroxidase activity with $3 \% \mathrm{H}_{2} \mathrm{O}_{2}$ (cat. no. 10011218; Sinopharm Chemical Reagent Co., Ltd., Shanghai, China) for $10 \mathrm{~min}$ at room temperature away from light, and incubated with the TUNEL reaction mixture (Enzyme solution vs. Label Solution, 1:9) for $1 \mathrm{~h}$ at $37^{\circ} \mathrm{C}$. Subsequently, cells were stained with $0.8 \%$ hematoxylin for $3 \mathrm{~min}$ at room temperature. The apoptotic index was evaluated in 5 random fields per section under a fluorescence microscope (magnification, x200) and counted for each group.

Statistical analysis. All statistical analyses were performed using SPSS 16.0 software (SPSS, Inc., Chicago, IL, USA). All results are expressed as the mean \pm standard deviation. Comparisons among various groups were determined using one-way analysis of variance followed by the post hoc least significant difference test. $\mathrm{P}<0.05$ was considered to indicate a statistically significant difference.

\section{Results}

Inhibition of miR-205 in the myocardial tissue of CHF rats following short-term VNS treatment. As presented in Fig. 1A and B, miR-205 was screened by microarray analysis in our previous study (16), which revealed that the expression level of miR-205 was significantly increased in the CHF-SS group ( $\mathrm{n}=3 ; \mathrm{P}=0.022$ vs. SO-SS group) and markedly decreased in the CHF-VNS group ( $\mathrm{n}=4 ; \mathrm{P}=0.026$ vs. CHF-SS group) (16). As presented in Fig. 1C, these results were verified in cardiac tissue by RT-qPCR. The expression level of miR-205 in rats of the CHF-SS group was significantly activated compared with the SO-SS group $(4.48 \pm 1.15$ vs. $1.04 \pm 0.37, \mathrm{P}=0.002)$. Following short-term VNS, the expression level of miR-205 
A

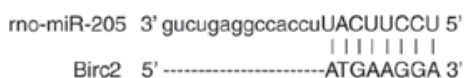

B

pmiR-Glo-Birc2-3'UTR tgtgcgtacgittctctcatgaATGAAGGAagctgtctgaacaaagaattactgattcag (wild-type)

pmiR-Glo-Birc2-3'UTR tgtgcgtacgittctctcatgaTACTCACTagctgtctgaacaaagaattactgattcag (mutant)

C
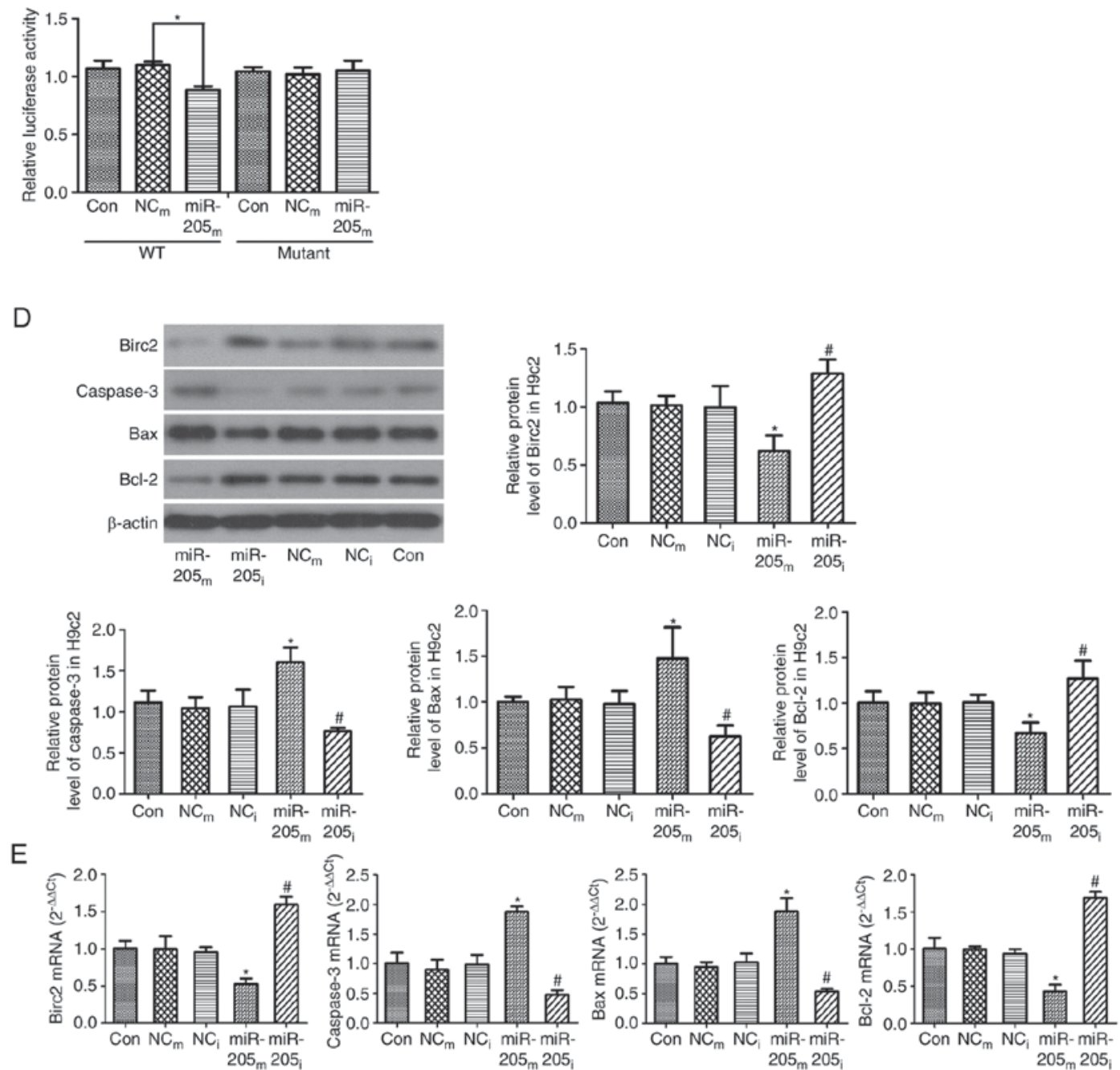

Figure 2. Birc2 is a target of miR-205 and downregulation of miR-205 reduces cell apoptosis in H9c2 cells. (A) Sequence alignment of miR-205 and 3'UTR of Birc2. (B) 3'UTR of Birc2 or a mutated sequence was cloned into pmiR-Glo vector. (C) Luciferase reporter assay with co-transfection of wild-type or mutant 3'UTR and miR-205 ${ }_{\mathrm{m}}$ or $\mathrm{NC}_{\mathrm{m}}$ in 293T cells. (D) Protein and (E) mRNA expression levels of Birc2, caspase-3, Bax and Bcl-2 in H9c2 cells transfected with miR-205 as an internal control. $\beta$-actin served as a loading control. Data are expressed as the mean \pm standard deviation. ${ }^{*} \mathrm{P}<0.05$ vs. $\mathrm{NC}_{\mathrm{m}}$; ${ }^{\prime \prime} \mathrm{P}<0.05$ vs. $\mathrm{NC}_{\mathrm{i}} \cdot$ miR-205 $\mathrm{m}$, miR-205 mimics; miR-205 ${ }_{\mathrm{i}}$, miR-205 inhibitor; $\mathrm{NC}_{\mathrm{m}}$, negative control mimics; $\mathrm{NC}_{\mathrm{i}}$, negative control inhibitor; Birc2, baculoviral IAP repeat-containing protein 2; miR, microRNA; 3'UTR, 3-untranslated region; Con, control; WT, wild-type; Bax, Bcl-2-associated X protein; Bcl-2, B-cell lymphoma 2.

was gradually inhibited in CHF-VNS group compared with the CHF-SS group ( $2.38 \pm 0.55$ vs. $4.48 \pm 1.15, \mathrm{P}=0.015)$.

Downregulation of miR-205 targeted to increase the expression of Birc2 and further reduce cell apoptosis. For predicting the potential target gene of miR-205, the present study implemented a bioinformatic analysis using miRanda, TargetScan and miRWalk algorithm. It was demonstrated that Birc2 theoretically included an miR-205 binding site in the 3'UTR (Fig. 2A). Birc2 is one of the inhibitor of apoptosis proteins, and its activation results in cell anti-apoptosis and cytoprotection. Studies have demonstrated that miR-205 accelerates cell apoptosis (20-22); the present study supported this by indicating that miR-205 may regulate Birc2. To verify this hypothesis, the present study cloned the 3'UTR of Birc2 into a pmiR-Glo-Birc2 vector (Fig. 2B) and co-transfected miR-205 mimics/inhibitor into the vector in $293 \mathrm{~T}$ cells. Co-transfection of miR-205 inhibited the luciferase activity of the reporter, including wild-type pmiR-Glo-Birc2-3'UTR sequence $(0.88 \pm 0.03$ vs. $1.09 \pm 0.01, P<0.001$, vs. negative control group; Fig. 2C), but failed to suppress that of mutant pmiR-Glo-Birc2 by dual luciferase reporter gene assay ( $\mathrm{P}>0.05$ vs. negative control group; Fig. 2C). These data suggested that miR-205 could directly target the 3'UTR sequences of pmiR-Glo-Birc2. 


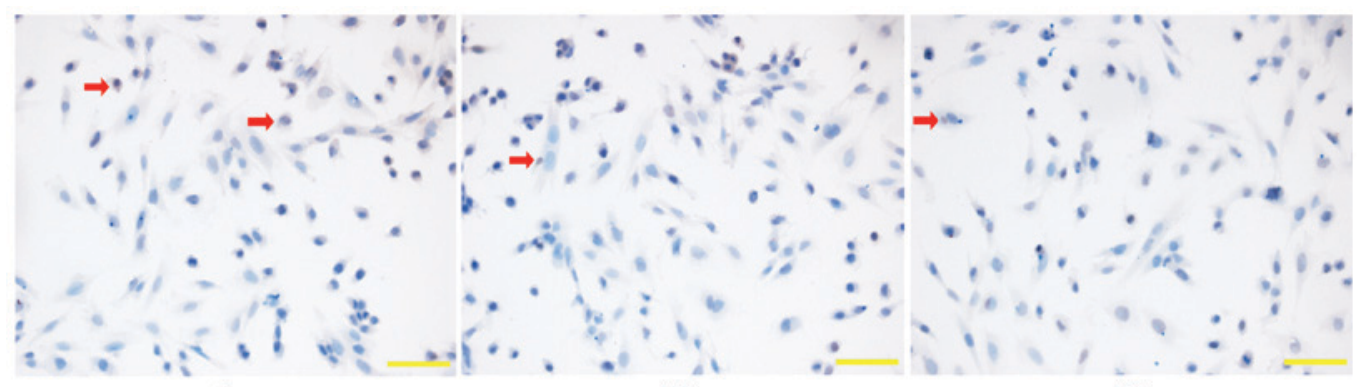

Con

$\mathrm{NC}_{\mathrm{m}}$

$\mathrm{NC}$
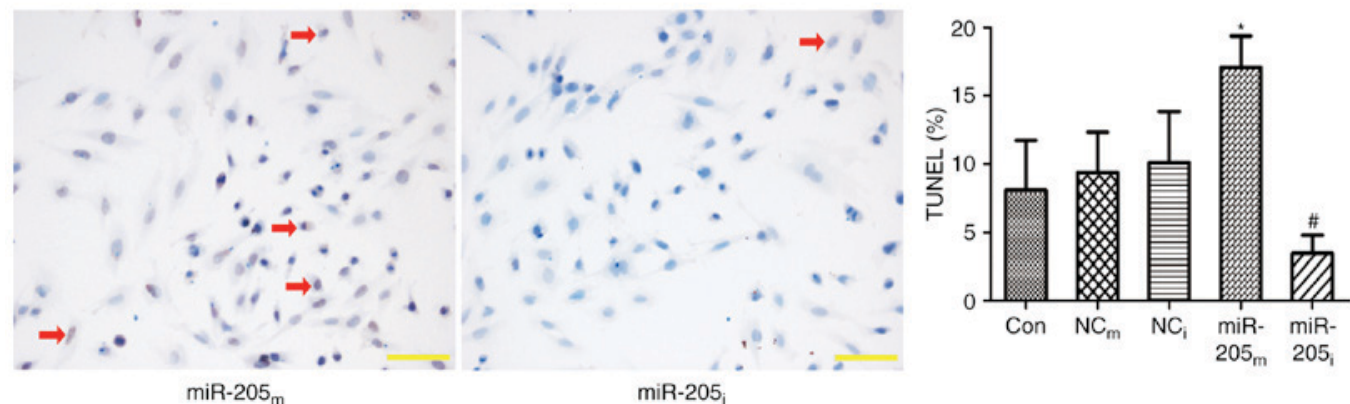

Figure 3. TUNEL assay in H9c2 cells transfected with miR-205. Representative microscope images. Magnification, x200. The red arrows indicate the apop-

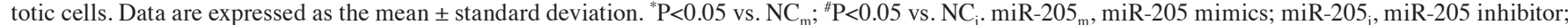
$\mathrm{NC}_{\mathrm{m}}$, negative control mimics; $\mathrm{NC}_{\mathrm{i}}$, negative control inhibitor; Con, control; TUNEL, TdT-mediated dUTP nick end labeling assay.

Additionally, the protein expression level of Birc2 was significantly suppressed by miR-205 mimic transfection in H9c2 cells $\left(0.62 \pm 0.13\right.$ vs. $1.02 \pm 0.08, \mathrm{P}=0.003$ vs. $\mathrm{NC}_{\mathrm{m}}$ group), while the expression was markedly increased by the miR-205 inhibitor (1.28 \pm 0.11 vs. $0.99 \pm 0.19, \mathrm{P}=0.02$ vs. $\mathrm{NC}_{\mathrm{i}}$ group; Fig. $\left.2 \mathrm{D}\right)$. All these findings demonstrated that miR-205 targets and regulates Birc2 protein expression. They also suggested that inhibition of miR-205 expression could serve an anti-apoptotic function by increasing Birc2 expression.

Furthermore, for clarifying the mechanisms of apoptosis, RT-qPCR and western blot analyses were performed to measure the expression levels of Birc2, caspase-3, Bax and Bcl-2. As presented in Fig. 2D, the protein expression levels of caspase- 3 and Bax were higher in the miR-205 $\mathrm{m}$ group compared with the $\mathrm{NC}_{\mathrm{m}}$ group $(1.61 \pm 0.18$ vs. $1.05 \pm 0.13$ and $1.48 \pm 0.34$ vs. $1.03 \pm 0.14, \mathrm{P}=0.001$ and $\mathrm{P}<0.014$, respectively), and were markedly decreased in the miR-205 group compared with the $\mathrm{NC}_{\mathrm{i}}$ group $(0.76 \pm 0.04$ vs. $1.06 \pm 0.21$ and $0.63 \pm 0.12$ vs. $0.98 \pm 0.14, \mathrm{P}=0.036$ and $\mathrm{P}=0.042$, respectively). The protein expression level of $\mathrm{Bcl}-2$ was lower in the miR-205 $\mathrm{m}$ group $\left(0.67 \pm 0.12\right.$ vs. $0.99 \pm 0.12, \mathrm{P}=0.015$ vs. $\mathrm{NC}_{\mathrm{m}}$ group), and was markedly higher in the miR-205 group $(1.27 \pm 0.2$ vs. $1.01 \pm 0.09$, $\mathrm{P}=0.037$ vs. $\mathrm{NC}_{\mathrm{i}}$ group).

As presented in Fig. 2E, consistent with the western blot results, the mRNA expression levels of caspase- 3 and Bax were significantly increased in the miR-205 $\mathrm{m}$ group compared with the $\mathrm{NC}_{\mathrm{m}}$ group $(1.88 \pm 0.09$ vs. $0.90 \pm 0.17$ and $1.88 \pm 0.22$ vs. $0.95 \pm 0.08, \mathrm{P}<0.001$, respectively); however, the levels of caspase- 3 and Bax were lower in the miR-205 ${ }_{i}$ group compared with the $\mathrm{NC}_{\mathrm{i}}$ group $(0.48 \pm 0.07$ vs. $0.98 \pm 0.17$ and $0.54 \pm 0.05$ vs. $1.03 \pm 0.15, \mathrm{P}=0.001$, respectively). The $\mathrm{mRNA}$ expression levels of Birc2 and Bcl-2 were markedly lower in the miR-205 group compared with the $\mathrm{NC}_{\mathrm{m}}$ group $(0.52 \pm 0.08$ vs. $0.99 \pm 0.18$ and $0.43 \pm 0.09$ vs. $0.99 \pm 0.04, \mathrm{P}<0.001$ respectively). However, the levels of Birc2 and Bcl-2 were increased in the miR-205 group compared with the $\mathrm{NC}_{\mathrm{i}}$ group $(1.60 \pm 0.11$ vs. $0.95 \pm 0.07$ and $1.69 \pm 0.08$ vs. $0.94 \pm 0.06, P=0.001$ respectively). These data demonstrated that downregulation of miR-205 reduced cell apoptosis.

TUNEL assay was also performed to evaluate apoptosis of $\mathrm{H} 9 \mathrm{c} 2$ cells transfected with the miR-205 vector. As presented in Fig. 3, the apoptosis of $\mathrm{H} 9 \mathrm{c} 2$ cells was markedly increased in the miR-205 ${ }_{\mathrm{m}}$ group $(13.61 \pm 1.44$ vs. $8.21 \pm 1.56, \mathrm{P}<0.001$ vs. $\mathrm{NC}_{\mathrm{m}}$ group), while the apoptosis was markedly reduced in the miR-205i group $\left(4.96 \pm 0.70\right.$ vs. $8.27 \pm 0.94, \mathrm{P}<0.001$ vs. $\mathrm{NC}_{\mathrm{i}}$ group).

Anti-apoptosis effect in the myocardial tissue of rats with CHF following short-term VNS treatment. The above studies demonstrated that miR-205 mediates Birc2 to reduce myocardial apoptosis. To further determine the anti-apoptosis effect of short-term VNS treatment in the myocardial tissue of $\mathrm{CHF}$ rats, the present measured the expression levels of Birc2, caspase-3, Bax and Bcl-2 using RT-qPCR and western blot analyses in the three experimental groups of rats. As presented in Fig. 4A, the mRNA expression levels of caspase-3 and Bax were significantly increased in the CHF-SS group compared with the SO-SS group $(2.07 \pm 0.13$ vs. $1.05 \pm 0.4$ and $2.63 \pm 0.48$ vs. $1.01 \pm 0.19, \mathrm{P}=0.004$ and $\mathrm{P}=0.001$, respectively) and were reduced in the CHF-VNS group compared with the CHF-SS group $(1.39 \pm 0.23$ vs. $2.07 \pm 0.13$ and $1.65 \pm 0.15$ vs. $2.63 \pm 0.48$, $\mathrm{P}=0.023$ and $\mathrm{P}=0.008$, respectively). The mRNA expression levels of Birc2 and Bcl-2 were markedly lower in the CHF-SS group compared with the SO-SS group $(0.37 \pm 0.14$ vs. $1.01 \pm 0.21$ and $0.44 \pm 0.05$ vs. $1.02 \pm 0.22, \mathrm{P}=0.002$ and $\mathrm{P}=0.004$, respectively) and were increased in the CHF-VNS group compared with the CHF-SS group $(0.78 \pm 0.1$ vs. $0.37 \pm 0.14$ and $0.87 \pm 0.14$ vs. $0.44 \pm 0.05, \mathrm{P}=0.018$ and $\mathrm{P}=0.016$, respectively).

As presented in Fig. 4B, consistent with the RT-qPCR results, the protein expression levels of caspase- 3 and Bax 

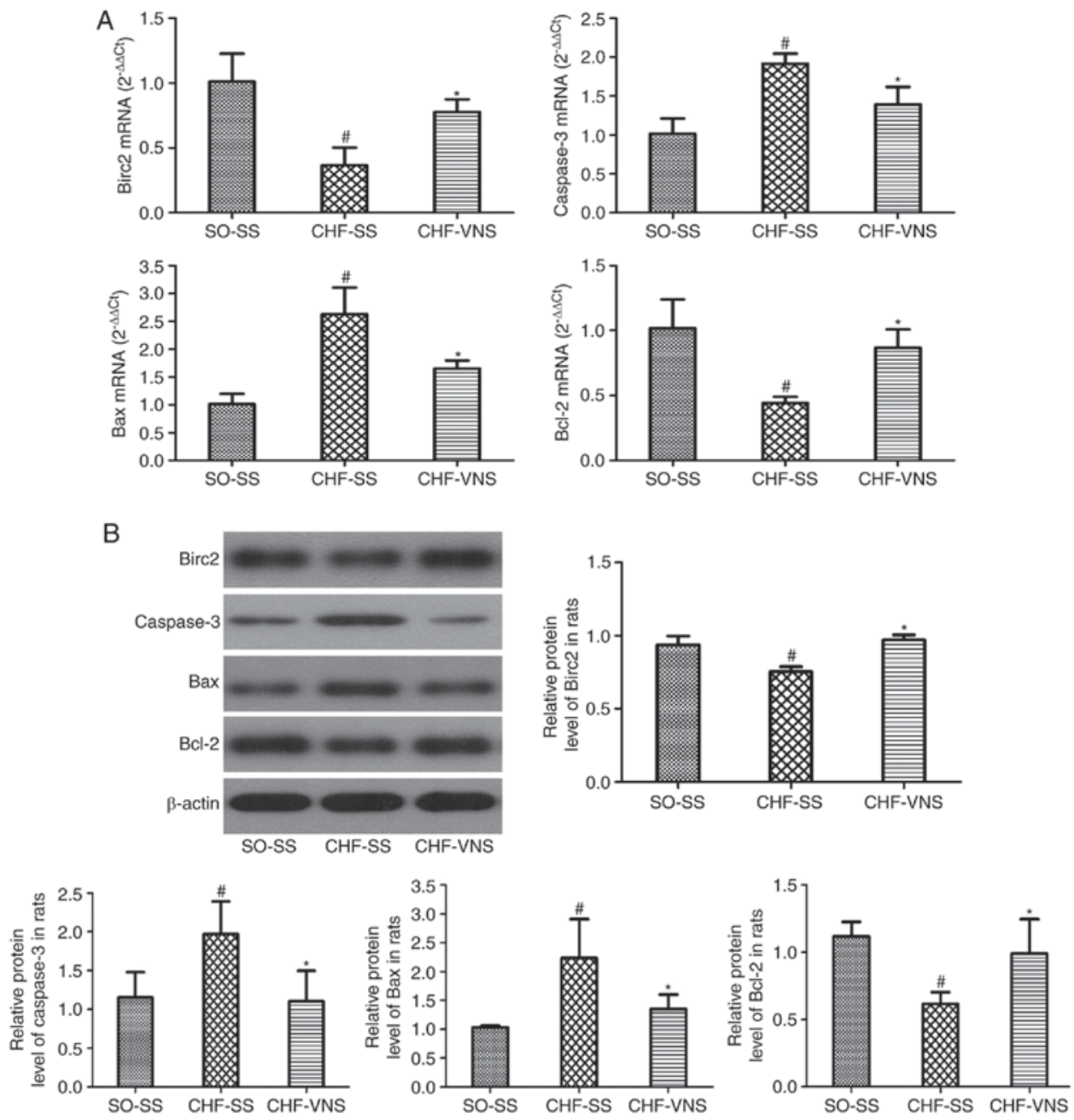

Figure 4. mRNA and protein expression levels of apoptosis-associated factors in the SO-SS, CHF-SS and CHF-VNS groups (n=8/group). (A) mRNA and (B) protein expression levels of Birc2, caspase-3, Bax and Bcl-2. $\beta$-actin served as an internal control. Data are expressed as the mean \pm standard deviation ${ }^{\#} \mathrm{P}<0.05$ vs. SO-SS; "P<0.05 vs. CHF-SS. miR, microRNA; SO, sham-operated; CHF, chronic heart failure; SS, sham stimulation; VNS, vagus nerve stimulation; Bax, Bcl-2-associated X protein; Bcl-2, B-cell lymphoma 2; Birc2, baculoviral IAP repeat-containing protein 2.

were significantly higher in the CHF-SS group compared with the SO-SS group $(1.97 \pm 0.42$ vs. $1.15 \pm 0.33$ and $2.23 \pm 0.68$ vs. $1.03 \pm 0.03, \mathrm{P}=0.041$ and $\mathrm{P}=0.012$, respectively). Following short-term VNS, the levels of caspase-3 and Bax were markedly lower in the CHF-VNS group compared with the CHF-SS group $(1.10 \pm 0.39$ vs. $1.97 \pm 0.42$ and $1.35 \pm 0.25$ vs. $2.23 \pm 0.68$, $\mathrm{P}=0.033$ and $\mathrm{P}=0.042$, respectively). The protein expression levels of Birc2 and Bcl-2 in the CHF-SS group were significantly reduced compared with the SO-SS group $(0.75 \pm 0.04$ vs. $0.94 \pm 0.06$ and $0.62 \pm 0.09$ vs. $1.12 \pm 0.11, P=0.002$ and $\mathrm{P}=0.011$, respectively). Following short-term VNS, the level of Birc2 and Bcl-2 were markedly higher in the CHF-VNS group compared with the CHF-SS group $(0.97 \pm 0.03$ vs. $0.75 \pm 0.04$ and $0.99 \pm 0.26$ vs. $0.62 \pm 0.09, P=0.001$ and $\mathrm{P}=0.034$, respectively). All these findings suggested that short-term VNS treatment serves an anti-apoptosis effect in the myocardial tissue of rats following CHF.

\section{Discussion}

Heart failure is the dysfunction of contraction and/or diastole, leading to insufficiency of blood circulation in the heart, and is a major cause of mortality from cardiovascular disease $(1,23,24)$. The morbidity of HF is increased with the aging population (25). The clinical treatments of HF have made more progress; however, traditional therapies are insufficient for many patients with HF, who eventually progress to end-stage disease (1). Animal experiments and clinical investigations have reported that VNS treatment improves the cardiac function and prognosis of $\mathrm{CHF}$, and reduces the fatality rate (26-28). Our previous study demonstrated that short-term VNS has a significant beneficial effect on attenuation of LV remodeling, alters the components of cardiac excitation-contraction coupling associated protein, and improves the cardiac function in rats with CHF (5).

miRNAs participate in regulating gene expression in different diseases. Previous research has demonstrated that regulating the expression of miRNAs serves a protective role in HF (29-32). The present study demonstrated that short-term VNS reduces miR-205 expression in CHF-VNS rats. miR-205 serves a different role in diverse range of tumor cell types (33-36). miR-205 induces inflammation and atherosclerosis in vascular endothelial cells and targets to regulate tissue inhibitor of metalloproteinase 3 , which serves 
a protective role in vascular endothelial cells through interfering the expression of miR-205 (37,38). miR-205 was also demonstrated to regulate the expression of phosphatase and tensin homolog directly in endometrial cancer cells, as well as inhibit apoptosis (39). Myocardial apoptosis serves an important role in the development of HF. A variety of myocardial cell injuries, such as myocardial infarction, ischemia/reperfusion, and genetic and metabolic cardiomyopathy, can induce myocardial apoptosis and eventually develop into HF; thus, it is a potential therapeutic target to reduce myocardial damage. Apoptosis is tightly regulated by a variety of active and programmed death processes under certain physiological or pathological conditions, and it is an important homeostatic mechanisms (40). Birc2 is a member of the anti-apoptotic gene family, which mainly serves its function by inhibiting the activation of caspase-3, 7, 9 and other enzymes (41). Endoplasmic reticulum stress induces the Birc2 expression of inhibition apoptosis through the phosphoinositide 3-kinase/protein kinase B signaling pathway and serves an important role in the adaptation of cellular stress $(42,43)$. Caspase-3 is a common downstream effector of the apoptosis signaling pathway. Bcl-2 and Bax are involved in cell survival and apoptosis via regulating the mitochondria. Bcl-2 is a direct effect of the substrate caspase-3, and the N-terminal variable loop region can be cut by caspase-3 at Asp34, and cleave fragments of similar Bax, overall promoting apoptosis (44). Birc2, caspase-3, Bcl-2 and Bax can interact and influence each other, so as to participate in the regulation of apoptosis.

The present study demonstrated that miR-205 is involved in VNS treatment by regulating myocardial apoptosis in CHF, and downregulating miR-205 increased the expression of Birc2 in vitro. The present study also investigated the mRNA and protein expression levels of caspase-3, Bax and Bcl-2. Prior to short-term VNS treatment, the expression levels of caspase-3 and Bax were higher and that of Bcl-2 was significantly lower in the CHF-SS group compared with the SO-SS group. After short-term VNS therapy, the expression levels of Bax and caspase-3 were lower and Bcl-2 was significantly higher in the CHF-VNS group compared with the CHF-SS group. To confirm these results in vitro, the present study demonstrated that the upregulation of miR-205 increased the mRNA and protein expression levels of caspase- 3 and Bax, and decreased Birc2 and Bcl-2; however, the downregulation of miR-205 served the opposite effect. TUNEL assay revealed consistent results; myocardial apoptosis was increased by upregulation of miR-205, but decreased by downregulation of miR-205. These results indicated that the downregulation of miR-205 was one significant reason for which short-term VNS treatment improved heart function in $\mathrm{CHF}$.

In conclusion, the present study demonstrated that short-term VNS therapy decreases apoptosis and serves a protective role in cardiomyocytes by downregulating miR-205, and improved cardiac function in rats with $\mathrm{CHF}$. Therefore, the results of the present study provide basic evidence for the application of short-term VNS in clinical treatments for $\mathrm{CHF}$.

\section{Acknowledgements}

The present study was supported by Liaoning Provincial Science and Technology Department (grant no. 2011404013-7).

\section{References}

1. Akat KM, Moore-McGriff D, Morozov P, Brown M, Gogakos T, Correa Da Rosa J, Mihailovic A, Sauer M, Ji R, Ramarathnam A, et al: Comparative RNA-sequencing analysis of myocardial and circulating small RNAs in human heart failure and their utility as biomarkers. Proc Natl Acad Sci USA 111: 11151-11156, 2014

2. Schwartz PJ, De Ferrari GM, Sanzo A, Landolina M, Rordorf R, Raineri C, Campana C, Revera M, Ajmone-Marsan N, Tavazzi L and Odero A: Long term vagal stimulation in patients with advanced heart failure: First experience in man. Eur J Heart Fail 10: 884-891, 2008.

3. Sabbah HN, Ilsar I, Zaretsky A, Rastogi S, Wang M and Gupta RC: Vagus nerve stimulation in experimental heart failure. Heart Fail Rev 16: 171-178, 2011.

4. Zannad F, De Ferrari GM, Tuinenburg AE, Wright D, Brugada J, Butter C, Klein H, Stolen C, Meyer S, Stein KM, et al: Chronic vagal stimulation for the treatment of low ejection fraction heart failure: Results of the neural cardiac therapy for heart failure (NECTAR-HF) randomized controlled trial. Eur Heart J 36: 425-433, 2015.

5. Li Y, Xuan YH, Liu SS, Dong J, Luo JY and Sun ZJ: Short-term vagal nerve stimulation improves left ventricular function following chronic heart failure in rats. Mol Med Rep 12: 1709-1716, 2015.

6. Bartel DP: MicroRNAs: Genomics, biogenesis, mechanism, and function. Cell 116: 281-297, 2004.

7. Barringhaus KG and Zamore PD: MicroRNAs: Regulating a change of heart. Circulation 119: 2217-2224, 2009.

8. Cordes KR and Srivastava D: MicroRNA regulation of cardiovascular development. Circ Res 104: 724-732, 2009.

9. Eulalio A, Mano M,Dal Ferro M,Zentilin L, Sinagra G,Zacchigna S and Giacca M: Functional screening identifies miRNAs inducing cardiac regeneration. Nature 492: 376-381, 2012.

10. Latronico MV and Condorelli G: MicroRNAs and cardiac pathology. Nat Rev Cardiol 6: 419-429, 2009.

11. Olivetti G, Abbi R, Quaini F, Kajstura J, Cheng W, Nitahara JA, Quaini E, Di Loreto C, Beltrami CA, Krajewski S, et al: Apoptosis in the failing human heart. N Engl J Med 336: 1131-1141, 1997.

12. Wencker D, Chandra M, Nguyen K, Miao W, Garantziotis S, Factor SM, Shirani J, Armstrong RC and Kitsis RN: A mechanistic role for cardiac myocyte apoptosis in heart failure. J Clin Invest 111: 1497-1504, 2003.

13. Katz MG, Fargnoli AS, Williams RD, Kendle AP, Steuerwald NM and Bridges CR: MiRNAs as potential molecular targets in heart failure. Future Cardiol 10: 789-800, 2014.

14. Xu C, Lu Y, Pan Z, Chu W, Luo X, Lin H, Xiao J, Shan H, Wang $\mathrm{Z}$ and Yang B: The muscle-specific microRNAs miR-1 and miR-133 produce opposing effects on apoptosis by targeting HSP60, HSP70 and caspase-9 in cardiomyocytes. J Cell Sci 120: 3045-3052, 2007.

15. Tang Y, Zheng J, Sun Y, Wu Z, Liu Z and Huang G: MicroRNA-1 regulates cardiomyocyte apoptosis by targeting Bcl-2. Int Heart J 50: 377-387, 2009.

16. Liu SS, Xuan YH, Li Y, Dong J, Luo JY and Sun ZJ: Short-term vagal nerve stimulation improves chronic heart failure via miR-133a-3p upregulation in a rat model. Int J Clin Exp Pathol 10: 50-60, 2017.

17. Cao JM, Fishbein MC, Han JB, Lai WW, Lai AC, Wu TJ, Czer L, Wolf PL, Denton TA, Shintaku IP, et al: Relationship between regional cardiac hyperinnervation and ventricular arrhythmia. Circulation 101: 1960-1969, 2000.

18. Gajarsa JJ and Kloner RA: Left ventricular remodeling in the post-infarction heart: A review of cellular, molecular mechanisms, and therapeutic modalities. Heart Fail Rev 16: 13-21, 2011.

19. Livak KJ and Schmittgen TD: Analysis of relative gene expression data using real-time quantitative PCR and the 2(-Delta Delta C(T)) method. Methods 25: 402-408, 2001.

20. Salajegheh A, Vosgha H, Md Rahman A, Amin M, Smith RA and Lam AK: Modulatory role of miR-205 in angiogenesis and progression of thyroid cancer. J Mol Endocrinol 55: 183-196, 2015.

21. Guan B, Li Q, Li XH and Zhou XJ: MicroRNA-205 targeted Kruppel-like factor 12 and regulated MDA-MB-468 cells apoptosis in basal-like breast carcinoma. Zhonghua Yi Xue Za Zhi 96: 2070-2075, 2016 (In Chinese).

22. Tian L, Zhang J, Ge J, Xiao H, Lu J, Fu S, Liu M and Sun Y: MicroRNA-205 suppresses proliferation and promotes apoptosis in laryngeal squamous cell carcinoma. Med Oncol 31: 785, 2014. 
23. Gaddam KK, Verma A, Thompson M, Amin R and Ventura $\mathrm{H}$ : Hypertension and cardiac failure in its various forms. Med Clin North Am 93: 665-680, 2009.

24. Schannwell CM, Hennersdorf MG and Strauer BE: Hypertension and cardiac failure. Internist (Berl) 48: 909-920, 2007 (In German)

25. McMurray JJ, Adamopoulos S, Anker SD, Auricchio A, Böhm M, Dickstein K, Falk V, Filippatos G, Fonseca C, Gomez-Sanchez MA, et al: ESC Guidelines for the diagnosis and treatment of acute and chronic heart failure 2012: The task force for the diagnosis and treatment of acute and chronic heart failure 2012 of the European Society of Cardiology. Developed in collaboration with the Heart Failure Association (HFA) of the ESC. Eur Heart J 33: 1787-1847, 2012.

26. Hamann JJ, Ruble SB, Stolen C, Wang M, Gupta RC, Rastogi S and Sabbah HN: Vagus nerve stimulation improves left ventricular function in a canine model of chronic heart failure. Eur J Heart Fail 15: 1319-1326, 2013.

27. De Ferrari GM, Crijns HJ, Borggrefe M, Milasinovic G, Smid J, Zabel M, Gavazzi A, Sanzo A, Dennert R, Kuschyk J, et al: Chronic vagus nerve stimulation: A new and promising therapeutic approach for chronic heart failure. Eur Heart J 32: 847-855, 2011.

28. Premchand RK, Sharma K, Mittal S, Monteiro R, Dixit S, Libbus I, DiCarlo LA, Ardell JL, Rector TS, Amurthur B, et al: Autonomic regulation therapy via left or right cervical vagus nerve stimulation in patients with chronic heart failure: Results of the ANTHEM-HF trial. J Card Fail 20 808-816, 2014

29. Li X, Zhang X, Wang T, Sun C, Jin T, Yan H, Zhang J, Li X, Geng T, Chen $\mathrm{C}$, et al: Regulation by bisoprolol for cardiac microRNA expression in a rat volume-overload heart failure model. J Nanosci Nanotechnol 13: 5267-5275, 2013.

30. Tolonen AM, Magga J, Szabó Z, Viitala P, Gao E, Moilanen AM, Ohukainen P, Vainio L, Koch WJ, Kerkelä R, et al: Inhibition of Let-7 microRNA attenuates myocardial remodeling and improves cardiac function postinfarction in mice. Pharmacol Res Perspect 2: e00056, 2014.

31. Wong LL, Armugam A, Sepramaniam S, Karolina DS Lim KY, Lim JY, Chong JP, Ng JY, Chen YT, Chan MM, et al: Circulating microRNAs in heart failure with reduced and preserved left ventricular ejection fraction. Eur J Heart Fail 17: 393-404, 2015.

32. Kuosmanen SM, Hartikainen J, Hippeläinen M, Kokki H, Levonen AL and Tavi P: MicroRNA profiling of pericardial fluid samples from patients with heart failure. PLoS One 10: e0119646, 2015.
33. Wiklund ED, Bramsen JB, Hulf T, Dyrskjøt L, Ramanathan R, Hansen TB, Villadsen SB, Gao S, Ostenfeld MS, Borre M, et al: Coordinated epigenetic repression of the miR-200 family and miR-205 in invasive bladder cancer. Int J Cancer 128: 1327-1334, 2011.

34. Schaefer A, Jung M, Mollenkopf HJ, Wagner I, Stephan C, Jentzmik F, Miller K, Lein M, Kristiansen G and Jung K: Diagnostic and prognostic implications of microRNA profiling in prostate carcinoma. Int J Cancer 126: 1166-1176, 2010.

35. Karaayvaz M, Zhang C, Liang S, Shroyer KR and Ju J: Prognostic significance of miR-205 in endometrial cancer. PLoS One 7: e35158, 2012.

36. Matsushima K, Isomoto $\mathrm{H}$, Yamaguchi N, Inoue N, Machida $\mathrm{H}$, Nakayama T, Hayashi T, Kunizaki M, Hidaka S, Nagayasu T, et al: MiRNA-205 modulates cellular invasion and migration via regulating zinc finger E-box binding homeobox 2 expression in esophageal squamous cell carcinoma cells. J Transl Med 9: 30, 2011.

37. Son DJ, Kumar S, Takabe W, Kim CW, Ni CW, Alberts-Grill N, Jang IH, Kim S, Kim W, Won Kang S, et al: The atypical mechanosensitive microRNA-712 derived from pre-ribosomal RNA induces endothelial inflammation and atherosclerosis. Nat Commun 4: 3000, 2013.

38. Kim CW, Kumar S, Son DJ, Jang IH, Griendling KK and Jo H: Prevention of abdominal aortic aneurysm by anti-microRNA-712 or anti-microRNA-205 in angiotensin II-infused mice. Arterioscler Thromb Vasc Biol 34: 1412-1421, 2014.

39. Zhang G, Hou X, Li Y and Zhao M: MiR-205 inhibits cell apoptosis by targeting phosphatase and tensin homolog deleted on chromosome ten in endometrial cancer Ishikawa cells. BMC Cancer 14: 440, 2014.

40. Meier P, Finch A and Evan G: Apoptosis in development. Nature 407: 796-801, 2000

41. LaCasse EC, Baird S, Korneluk RG and MacKenzie AE: The inhibitors of apoptosis (IAPs) and their emerging role in cancer. Oncogene 17: 3247-3259, 1998.

42. Warnakulasuriyarachchi D, Cerquozzi S, Cheung $\mathrm{HH}$ and Holcik M: Translational induction of the inhibitor of apoptosis protein HIAP2 during endoplasmic reticulum stress attenuates cell death and is mediated via an inducible internal ribosome entry site element. J Biol Chem 279: 17148-17157, 2004.

43. Hamanaka RB, Bobrovnikova-Marjon E, Ji X, Liebhaber SA and Diehl JA: PERK-dependent regulation of IAP translation during ER stress. Oncogene 28: 910-920, 2009.

44. Kirsch DG, Doseff A, Chau BN, Lim DS, de Souza-Pinto NC, Hansford R, Kastan MB, Lazebnik YA and Hardwick JM: Caspase-3-dependent cleavage of Bcl-2 promotes release of cytochrome c. J Biol Chem 274: 21155-21161, 1999. 